\title{
$\alpha$-Klotho and catalase expression in essential hypertension
}

\author{
Gauri Pathare ${ }^{1}$, Sunila Raju ${ }^{1}$, Manoj Mashru ${ }^{2}$, Vinod Shah ${ }^{2}$ and Kavita Shalia ${ }^{1 *}$ \\ ${ }^{1}$ Sir HN Medical Research Society, Sir HN Reliance Foundation Hospital and Research Centre, Court House, L. T. Road, Mumbai 400002, India \\ ${ }^{2}$ Sir HN Reliance Foundation Hospital and Research Center, Raja Ram Mohan Roy Road, Mumbai 400004, India
}

\begin{abstract}
$\alpha$-Klotho, an anti-aging gene, has emerged as novel inhibitor of oxidative stress at cellular level. $\alpha$-Klotho inhibits oxidative stress by inhibiting IGF-1/InsulinFOXO (Forkhead box-O transcription factors) dependent deactivation of the antioxidative enzymes. The present study aimed at determining $\alpha$-Klotho and Catalase gene expressions and Catalase activity in peripheral blood mononuclear cells (PBMCs) of essential hypertensive patients as compared to normotensive healthy controls in Indian population. Forty-eight hypertensives and 48 age, BMI-matched controls were recruited. Gene expression was evaluated by quantitative Real-Time PCR. Catalase enzyme activity in PBMCs and soluble $\alpha$-Klotho levels in serum were detected using Enzyme-Linked Immunosorbent Assay. Gene expressions for $\alpha$-Klotho and FOXO1 were significantly low ( $\mathrm{p}<0.001$ and $\mathrm{p}=0.002$, respectively) in patients as compared to controls. Catalase expression was also low in hypertensive patients but did not reach statistical significance. However, there was strong positive correlation between $\Delta \mathrm{Ct}-\mathrm{based}$ gene expression of $\alpha$-Klotho and Catalase in patients $(\mathrm{p}<0.001)$ as well as controls $(\mathrm{p}=0.008)$. Positive correlation was also observed between gene expression of FOXO1 and that of $\alpha-\mathrm{Klotho}(\mathrm{p}=0.006)$ and Catalase $(\mathrm{p}=0.001)$ in hypertensives. Catalase activity in patients were significantly low ( $\mathrm{p}<0.001)$ as compared to controls and positively correlated with soluble $\alpha$-Klotho levels ( $r s=0.32, p=0.027$ ), which were also $30.2 \%$ lower $(\mathrm{p}<0.001)$ in the patient group. Present study demonstrates low soluble levels and gene expression of anti-aging protein $\alpha$-Klotho in hypertensive patients. $\alpha$-Klotho may influence Catalase expression in essential hypertension through its effect on FOXO1 expression.
\end{abstract}

\section{Introduction}

Essential hypertension is probably the most studied but least understood of the complex human disorders [1]. It is currently recognized as a multifactorial disease arising from the combined action of several genetic and environmental factors. Numerous physiological mechanisms are involved in the maintenance of normal blood pressure (BP), and an aberration in any one of these may play a part in the development of essential hypertension [2]. Recent studies have highlighted arterial aging as a risk factor for the development of hypertension $[3,4]$. $\alpha$-Klotho, an anti-aging gene identified by Kuro-o et al. was found to ameliorate aging phenotypes and extend lifespan. a-Klotho deficient transgenic mice exhibited several phenotypes resembling human aging including atherosclerosis, ectopic calcification in arterial walls and various soft tissues, pulmonary emphysema, cardiovascular diseases (CVD) and accelerated death [5]. Subsequent studies in animal models showed that $\alpha$-Klotho deficiency resulted in salt-sensitive hypertension [6]. Thus, $\alpha$-Klotho appears to be a link between aging and CVD including hypertension.

The $a$-Klotho gene encodes a single pass transmembrane protein consisting of intracellular, transmembrane and extracellular domains - and a circulating $\alpha$-Klotho protein. This circulating $\alpha$-Klotho acts as a peptide hormone and influences various signalling pathways including p53/p21, cAMP, protein kinase C, Wnt pathways as well as the Insulinlike growth factor-1 (IGF-1) signalling cascade [7]. The anti-aging effect of a-Klotho is partly attributed to increased resistance to oxidative stress at the cellular level via inhibition of insulin/IGF-1 signalling pathway: an evolutionarily conserved mechanism for extending life span [7]. Furthermore, the role of insulin/IGF-1 signalling pathway in hypertension has been well documented and serum IGF-1 levels are found to be elevated in hypertensive subjects $[8,9]$. Oxidative stress is one of the fundamental mechanisms responsible for the development of essential hypertension. The superoxide dismutases (SOD) and Catalase comprise the first line of defence system against ROS. Impaired activity of these enzymes has been associated with uncontrolled production of ROS and other free radicals [10]. $\alpha$-Klotho inhibits ROS and oxidative stress by inhibiting IGF-1/Insulin-FOXO (Forkhead box-O transcription factors) dependent deactivation of these antioxidant enzymes [11,12].

a-Klotho initiates a signalling cascade that begins with its binding to a yet unidentified a-Klotho receptor on the cell membrane, inhibiting the tyrosine kinase activity of the insulin/IGF-1 receptor [13], and subsequently the insulin receptor substrates. FOXOs are the downstream targets of insulin-like signalling that regulate organismal aging [14-17]. FOXO proteins mediate the inhibitory action of insulin / IGF-1 on key functions in diverse pathways including cell metabolism, proliferation, differentiation, oxidative stress, cell survival and senescence, autophagy and aging in mammals [18]. Thus, $\alpha$-Klotho regulates the FOXOs via inhibition of insulin/IGF-1 pathway. A recent study in cell lines demonstrated that $\alpha$-Klotho inhibited PI3K/AKTmediated phosphorylation of FOXO3a and subsequently enhanced FOXO3a binding to the Mn-SOD promoter, thereby leading to $a$-Klotho increased Mn-SOD mRNA and protein expression in mitochondria [19].

Yamamoto et al. found the effect of $\alpha$-Klotho protein was more pronounced on the FOXO1 than on the FOXO3a or FOXO4 proteins in

${ }^{*}$ Correspondence to: Kavita Shalia, Senior Scientist, HN Medical Research Society, HN Reliance Foundation Hospital and Research Centre, Court House, L. T. Road, Mumbai, India, Tel: 8451948222; E-mail: kavita.shalia@rfhospital.org

Key words: $\alpha$-Klotho, anti-aging gene, cardiovascular disease, gene expression, enzyme activity

Received: February 09, 2020; Accepted: February 22, 2020; Published: February 28,2020 
HeLa cells as well as murine models [11]. Further, Venkatesan et al. have reported the presence of FOXO1 DNA binding element in the promoter region of Catalase gene [20]. This study therefore aimed at analysing the expressions of $\alpha$-Klotho and Catalase as well as the activity of Catalase in PBMCs of hypertensive patients as compared to normotensive controls. The soluble levels of $\alpha$-Klotho were also analysed in both study groups. F2-isoprostanes, which are relatively stable and ubiquitous in human plasma and urine, have proven to be among the most sensitive and reliable biomarkers for the investigation of lipid peroxidation and hence oxidative stress in vivo [21,22]. Therefore, 8 -iso-prostaglandin F2 $\alpha$ (8-iso-PGF $2 \alpha$ ) levels were measured in serum of all subjects to quantitate the oxidative stress in the two study groups.

\section{Materials and methods}

\section{Study subjects}

Forty-eight patients diagnosed with essential hypertension (SBP/DBP $>140 / 90 \mathrm{mmHg}$ ) and 48 age and Body Mass Index (BMI) matched healthy normotensive $(\mathrm{SBP} / \mathrm{DBP}<120 / 80 \mathrm{mmHg})$ controls were recruited for the study. Hypertensive individuals were recruited in accordance with the Seventh Joint National Committee (JNC7) [23] report guidelines. The patients were referred to a consultant, immediately if SBP/DBP $\geq 160 / 100$ and after $6-8$ days of monitoring if $\mathrm{SBP} / \mathrm{DBP}<160 / 100$, before recruitment. On confirmation of essential hypertension, these patients were recruited under hypertension group after procuring their written informed consent. Detailed information regarding demographic status, clinical history, family history, and medication was obtained for all subjects. They did not show clinical symptoms or history of any other organic disease, and were not taking any medication. The study protocol was approved by the Institutional Ethics Committee, which follows the ethical standards laid down by the Indian Council of Medical Research's (ICMR) Ethical Guidelines for biomedical research on human participants.

\section{Sample collection and biochemical analyses}

Twelve-hour fasting venous blood samples were collected in plain and $\mathrm{K}_{2}$-EDTA vacutainers at the time of enrolment (for subjects identified with high BP, this sample was collected prior to starting hypertensive medication). Serum samples were used to perform routine biochemical investigations such as blood glucose, lipid profile, renal profile, and liver profile tests. Those healthy individuals with any test results beyond normal range were excluded from control group. Remaining serum was aliquoted and stored at $-80^{\circ} \mathrm{C}$ until further use.

\section{Oxidative stress levels (8-iso-PGF2 $\alpha$ )}

8-iso-PGF2 $\alpha$ levels were detected in serum and urine samples of patients and controls using Enzyme-Linked Immunosorbent Assay (ELISA) method (Immuno-Biological Laboratories Co., Ltd., Hamburg, Germany). Total 8-iso-PGF2 $\alpha$, both free and esterified, was measured by this method. Lipoprotein- or phospholipid-coupled 8-iso-PGF2a were hydrolysed as per manufacturer's instructions prior to the assay.

\section{Soluble a-Klotho levels}

Soluble $\alpha$-Klotho levels in serum samples were detected using ELISA according to manufacturer's instructions (Immuno-Biological Laboratories Co., Ltd., Hamburg, Germany).

\section{Catalase activity assay}

Enzyme activity of Catalase was measured in PBMC lysates using commercially available ELISA. PBMCs were isolated from $\mathrm{K}_{2}$-EDTA anti-coagulated blood using Ficoll- Histopaque ${ }^{\oplus}-1077$ (Sigma-Aldrich) gradient separation method. PBMCs were lysed in ice-cold phosphate buffered saline ( $1 \mathrm{mM}$ EDTA $)$ and the cell lysate was stored at $-80^{\circ} \mathrm{C}$ until further analysis. Catalase enzyme activity was measured using Oxiselect Activity assay kits (STA-341, Cell Biolabs, Inc, USA) as per manufacturer's instructions.

\section{RNA extraction and CDNA synthesis}

PBMCs were isolated from $\mathrm{K}_{2}$-EDTA anti-coagulated blood using Ficoll- Histopaque ${ }^{\bullet}-1077$ (Sigma-Aldrich) gradient separation method. RNA was extracted from the PBMCs by NucleoSpin RNA isolation kit (Macherey-Nagel, Düren, Germany). The quality and quantity of RNA was assessed using agarose gel electrophoresis and Qubit 2.0 Fluorometer, respectively. One microgram RNA was reverse transcribed to cDNA for each sample using PrimeScript $1^{\text {st }}$ strand cDNA Synthesis Kit (Takara Bio USA, Inc.) as per the manufacturer's instructions.

\section{Gene expression studies}

The gene expression was evaluated using quantitative Real time Polymerase Chain reaction (qRT-PCR) in StepOnePlus ${ }^{\mathrm{su}}$ Real-Time PCR System (Applied Biosystems) using TaqMan gene expression assays for a-Klotho (Hs00183100_m1), FOXO1 (Hs00231106_m1) and Catalase (Hs00156308_m1). The housekeeping gene GAPDH (Hs03929097_g1) was used as internal control. Relative gene expression was calculated according to the comparative Ct method $\left(2^{-\Delta \Delta \mathrm{Ct}}\right)$ described by Livak and Schmittgen [24]. All experiments were performed in duplicates according to the manufacturer's protocol.

\section{Statistical analyses}

Results are expressed as frequency, percentage and mean \pm standard deviation (SD) for parametric variables and median with inter quartile (25th/75th) ranges for non-parametric variables. Student's unpaired $t$ test and Mann-Whitney $U$ test were used to determine the significance of differences between the two study groups for parametric and non-parametric variables respectively. Correlations were evaluated by Spearman's rank correlation test. For all tests $\mathrm{p}$ value $<0.05$ was considered statistically significant. Analyses were performed using statistical software SPSS (version 21.0, Chicago, IL). For expression studies, patients were grouped according to their age, BMI and gender, and compared against corresponding matched healthy controls during each run of gene expression analysis using Taqman assays. Therefore, all correlations between the groups are for a total of 48 patients and corresponding 17 controls.

\section{Results}

\section{Demographic and clinical characteristics}

The baseline demographic characteristics of patients and controls are depicted in Table 1. The comparison of lipid profile of patients and controls, given in Table 2, did not differ significantly between the two groups.

\section{8-iso-Prostaglandin F2a levels}

In hypertensive patients, the levels of 8-iso-PGF2a were significantly high $(\mathrm{p}<0.001)$ in serum $(11.3$-fold/ $91.1 \%, \mathrm{p}<0.001)$ as compared to controls (Figure 1). In control group, 8-iso-PGF2 $\alpha$ levels negatively correlated with both soluble $\alpha$-Klotho levels ( $r s=-0.413, p=0.004$ ) and catalase activity ( $\mathrm{rs}=-0.344, \mathrm{p}=0.017)$. There was no correlation observed between this oxidative stress marker and lipid parameters. The intra- and inter-assay coefficients of variability $(\mathrm{CV})$ were $1.6 \%$ and 
Table 1. Comparison of demographic parameters between patient and control groups

\begin{tabular}{|c|c|c|}
\hline Parameters & Controls (N=48) & Patients (N=48) \\
\hline Age (years) & $45.8 \pm 6.7$ & $48.8 \pm 5.7$ \\
\hline Male $/$ Female & $43 / 5$ & $45 / 3$ \\
\hline BMI $\left(\mathrm{kg} / \mathrm{m}^{2}\right)$ & $26.3 \pm 3.9$ & $27.1 \pm 5.77$ \\
\hline SBP $(\mathrm{mmHg})$ & $124.6 \pm 7.7$ & $164.3 \pm 14.8^{* * *}$ \\
\hline DBP $(\mathrm{mmHg})$ & $79.58 \pm 6.0$ & $102.08 \pm 6.78^{* * *}$ \\
\hline
\end{tabular}

*Values are expressed as mean $\pm \mathrm{SD}$.

$\dagger^{* * *} \mathrm{p}<0.001$ compared to respective control groups

\$BMI, Body Mass Index; SBP, Systolic Blood Pressure, DBP, Diastolic Blood Pressure

Table 2. Comparison of lipid profile between patient and control groups

\begin{tabular}{|c|c|c|}
\hline Parameters & Controls $(\mathbf{N}=\mathbf{4 8})$ & Patients $\mathbf{N}=\mathbf{4 8})$ \\
\hline TC $(\mathrm{mg} / \mathrm{dL})$ & $169.6 \pm 34.4$ & $172.6 \pm 31.6$ \\
\hline HDL-C (mg/dL) & $38.8 \pm 11.6$ & $43.0 \pm 11.6$ \\
\hline TC / HDL-C & $4.6 \pm 1.3$ & $4.2 \pm 1.0$ \\
\hline Triglycerides (mg/dL) & $110.9 \pm 43.7$ & $126.5 \pm 69.7$ \\
\hline VLDL-C (mg/dL) & $22.2 \pm 8.7$ & $25.3 \pm 13.9$ \\
\hline LDL-C (mg/dL) & $108.6 \pm 30.2$ & $104.3 \pm 29.0$ \\
\hline LDL-C/ HDL-C & $2.9 \pm 1.1$ & $2.6 \pm 0.9$ \\
\hline
\end{tabular}

*Values are expressed as mean $\pm \mathrm{SD}$

$†$ TC: Total cholesterol; HDL-C: High density lipoprotein cholesterol; VLDL-C: Very low density lipoprotein cholesterol; LDL-C: Low density lipoprotein cholesterol

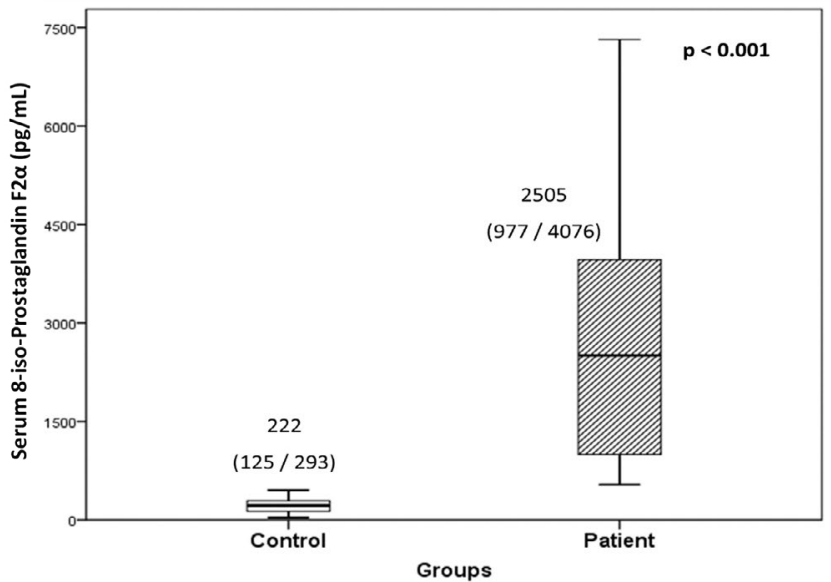

Figure 1. Serum levels of 8-iso-Prostaglandin F2 $\alpha$ in hypertensive patients and controls Values are expressed as median with interquartile (25th $/ 75$ th) range.

$1.4 \%$, respectively for serum levels. The intra- and inter-assay CV for urinary levels were $1.1 \%$ and $2.1 \%$, respectively.

\section{Soluble a-Klotho levels}

The levels of soluble $\alpha$-Klotho in serum of hypertensive patients were significantly low $(30.2 \%, \mathrm{p}=0.001)$ as compared to controls (Figure 2). The intra- and inter-assay CV were $0.7 \%$ and $3.0 \%$, respectively.

\section{Catalase activity assay}

In hypertensive patients, the enzyme activity of Catalase was found to be significantly low $(80.3 \%, \mathrm{p}<0.001)$ as compared to controls (Figure 3 ) and showed positive correlation with soluble $\alpha$-Klotho levels ( $\mathrm{rs}=0.32, \mathrm{p}=0.027)$. The intra-and inter- assay coefficients of CV for Catalase activity assays was $4.6 \%$ and $10.1 \%$, respectively.

\section{Gene expression studies}

The relative gene expression of $\alpha$-Klotho, FOXO1 and Catalase in were found to be 3.02 -fold, 1.55-fold and 1.23-fold lower, respectively, in hypertensive patients as compared to controls (Figure 4). The $\Delta \mathrm{Ct}$ values for the genes studied are given in Table 3. Based on $\Delta \mathrm{Ct}$ values, hypertensive patients showed significantly low $\alpha$-Klotho and FOXO1 gene expression $(\mathrm{p}<0.001$ and $\mathrm{p}=0.002$, respectively). Catalase expression was also low as compared to controls but did not reach statistical significance. However, positive correlation was observed between $\Delta \mathrm{Ct}$-based expressions of $\alpha$-Klotho and Catalase

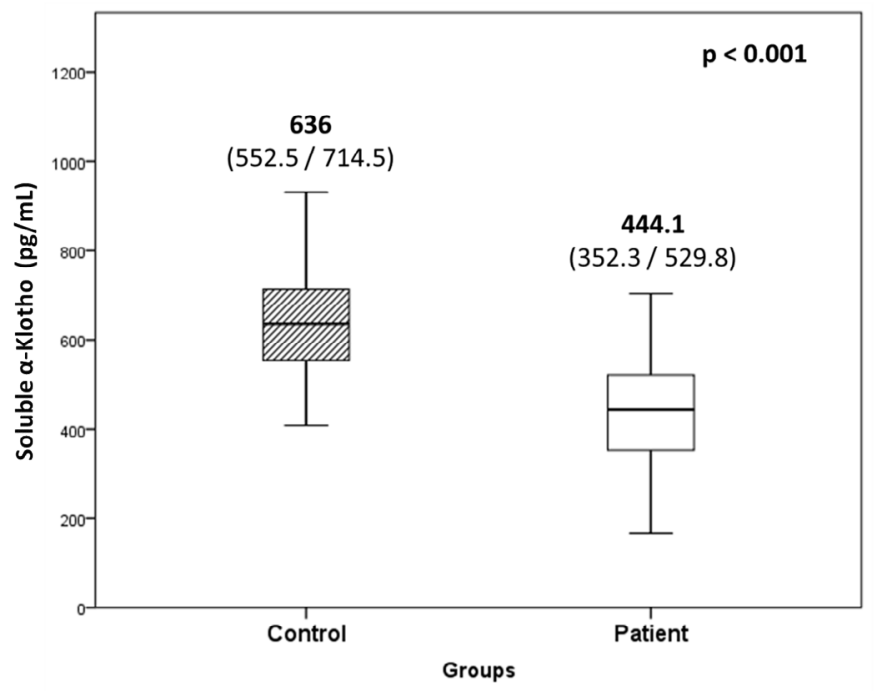

Figure 2. Soluble $\alpha$-Klotho levels in hypertensive patients and controls Values are expressed as median with interquartile (25th $/ 75$ th) range.

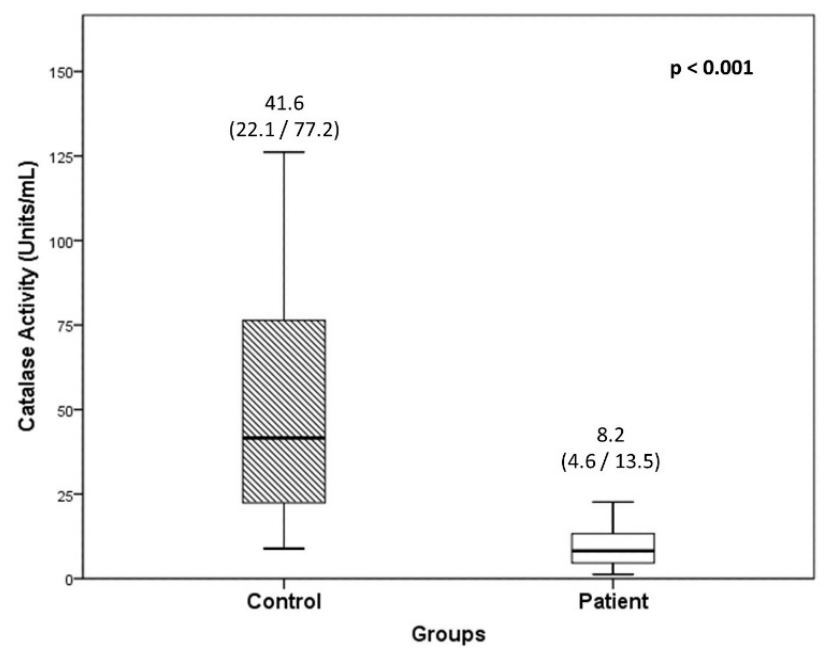

Figure 3. Catalase activity in PBMCs of hypertensive patients and controls Values are expressed as median with interquartile (25th $/ 75$ th) range.

Table 3. Gene expression based on $\Delta \mathrm{Ct}$ values of patients and controls

\begin{tabular}{|c|c|c|c|}
\hline \multirow[t]{2}{*}{ GENE } & \multicolumn{2}{|c|}{$\begin{array}{c}\Delta \mathrm{Ct} \text { values } \\
\text { Median }\left(25^{\text {th }} / \mathbf{7 5}^{\text {th }} \text { Percentile }\right)\end{array}$} & \multirow{2}{*}{$\begin{array}{c}\text { Significance } \\
\text { level } \\
\text { (p value) }\end{array}$} \\
\hline & Controls $(N=17)$ & Patients $(\mathrm{N}=\mathbf{4 8})$ & \\
\hline Klotho & $\begin{array}{c}\mathbf{1 4 . 9 3 8} \\
(14.278 / 16.244)\end{array}$ & $\begin{array}{c}\mathbf{1 6 . 9 3 6} \\
(15.943 / 18.556)\end{array}$ & 0.001 \\
\hline FOXO-1 & $\begin{array}{c}\mathbf{5 . 9 4 5} \\
(5.202 / 6.806)\end{array}$ & $\begin{array}{c}\mathbf{7 . 0 3 9} \\
(6.018 / 7.623)\end{array}$ & 0.002 \\
\hline Catalase & $\begin{array}{c}\mathbf{4 . 7 6 0} \\
(3.755 / 5.481)\end{array}$ & $\begin{array}{c}\mathbf{5 . 3 0 5} \\
(4.630 / 5.999)\end{array}$ & 0.076 \\
\hline
\end{tabular}



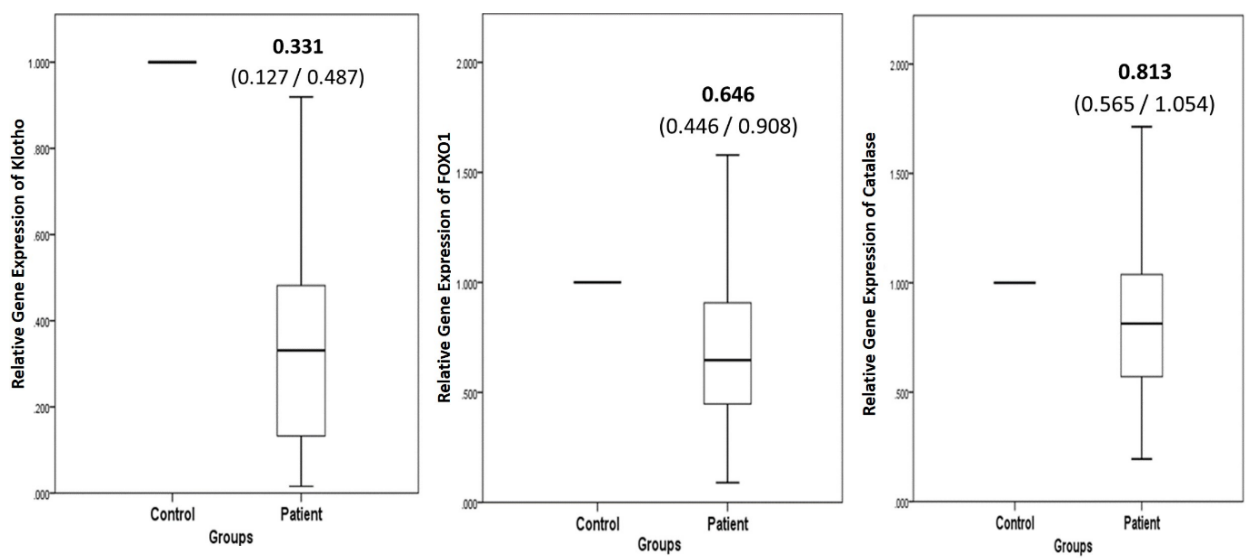

Figure 4. Relative gene expression levels for (a) Klotho, (b) FOXO1 and (c) Catalase in hypertensive patients compared to normotensive controls The gene expression of patients relative to that of controls are shown. Values are expressed as median with interquartile (25th $/ 75$ th) range.

in hypertensive $(\mathrm{rs}=0.753, \mathrm{p}<0.001)$ as well as in control $(\mathrm{rs}=0.618$, $\mathrm{p}=0.008$ ) groups. Furthermore, gene expression of FOXO1 positively correlated with that of $\alpha$-Klotho $(\mathrm{rs}=0.388, \mathrm{p}=0.006)$ and Catalase ( $\mathrm{rs}=0.471, \mathrm{p}=0.001)$ in the patient group.

\section{Discussion}

The present study observed a direct correlation between Catalase and $a$-Klotho gene expression in hypertensive patients as well as normotensive controls. Further, we also report significantly low expression of $\alpha$-Klotho in hypertensives as compared to controls. Both, the Catalase activity analysed in PBMCs and the soluble $\alpha$-Klotho levels in serum were significantly low in hypertensives as compared to controls and a significant positive correlation was observed between these two parameters in the patient group.

Evidence strongly suggests that oxidative stress, due to enhanced production of ROS and/or a decrease in the antioxidant reserve, is an important contributor to the development and persistence of hypertension. Previous studies in humans and animal models have established the state of increased oxidative stress in hypertension [2527]. The present study also found elevated 8-iso-PGF2a, a reliable marker of oxidative stress, in hypertensive patients accompanied by a significant decrease in Catalase activity.

The role of Catalase in hypertension has been previously studied and its overexpression has been reported to prevent hypertension in animal models [27]. Gomes et al. showed that Catalase activity was markedly downregulated in spontaneously hypertensive rat (SHR) cells as compared to control Wistar Kyoto (WKY) rat cells [28]. In a previous study, the same group has also reported downregulation of the protein expression level of Catalase in SHR cells [29]. Thus, the low activity and low expression of Catalase in SHR cells could increase vulnerability to oxidant-induced cell death [28]. Parallel to this finding, Zhan et al. demonstrated that providing antioxidant therapy to SHRs resulted in a significant increase in the Catalase enzymatic activity in their cortex and medulla [30]. Schriner et al. reported that overexpression of Catalase in transgenic mice helped removal of ROS in mitochondria and also extended their lifespan [31].

Similarly, Redón et al. also reported minimal Catalase activity in PBMCs of hypertensive patients [32]. The reason for this could be the inhibition of Catalase activity by increased levels of its own substrate i.e. $\mathrm{H}_{2} \mathrm{O}_{2}$, as demonstrated by Venkatesan et al. [20] and Sigfrid et al. [33], and could explain the lower Catalase activity observed in the present study in hypertensive patients. Moreover, in the present study in controls, overall Catalase activity was inversely related to 8-iso-PGF2a serum levels. This corroborates with the literature on deactivation of Catalase enzyme due to oxidative stress.

Alternatively, the lower activity of Catalase could be a result of its lower gene expression, which was also observed in hypertensive subjects of the present study as compared to controls. Similar finding has also been reported by Uddin et al. in aorta of a genetic model of hypertensive mice as compared to normotensive control mice, wherein Catalase gene expression was down regulated and its activity was significantly reduced [34]. Thus, downregulation of Catalase activity has been observed in hypertension.

A number of studies have explored the role of $\alpha$-Klotho in antioxidative systems and suggested that its anti-aging properties are a result of its ability to combat oxidative stress. In the present study, lower soluble $a$-Klotho levels were observed in hypertensive patients as compared to controls, which is in accordance with several previous reports. In Chinese population, Su \& Yang have attributed, albeit partially, the occurrence of systolic hypertension to reduction in serum a-Klotho levels [35]. The association of reduced circulating levels of a-Klotho with the occurrence and severity of coronary artery disease [36], CVD [37], and as an independent marker of arterial stiffness in patients with chronic kidney disease [38], have been reported in Spanish, Italian and Japanese cohorts respectively. The present study suggests that $\alpha$-Klotho levels are depleted in essential hypertension patients as well, and that this may be an important feature of the disease.

Klotho has been shown to be essential for maintenance of normal BP in mice models and significantly decreased Klotho gene and protein expression have been reported in SHRs as compared to the control WKY rats $[39,6]$. Similar to the present study, in humans as well, Xia et al. have also found lower gene expression of Klotho in PBMCs in atherosclerotic patients as compared to healthy controls [40] while Martín-Núñez et al. have reported lower vascular expression of Klotho gene in atherosclerotic disease [41]. Kuang et al. have reported that the age-related decrease in Klotho expression observed in mice, contributes to increased oxidative stress by enhancing FOXO phosphorylation and thus nuclear expulsion [42]. Furthermore, there are reports of repression of FOXO-1 expression by IGF1 $[43,44]$. Although previous studies have reported the regulation of Catalase expression by FOXO3a [45], other studies have implicated FOXO-1 in the regulation of Catalase expression [46,47]. Awad et al. have demonstrated that 
activation of AMP-activated protein kinase (AMPK), one of the kinases known to regulate FOXO1, led to increased FOXO1 (total and nuclear) protein as well as Catalase mRNA and protein content. Further, inhibition of AMPK inhibited FOXO1 and Catalase, but not FOXO3a [47]. The significance of FOXO1 is further demonstrated by the presence of FOXO1 DNA binding element in the Catalase promoter region [20]. Venkatesan et al. demonstrated that hydrogen peroxide $\left(\mathrm{H}_{2} \mathrm{O}_{2}\right)$ negatively regulated FOXO1 by PI3K/Akt-dependent phosphorylation, eventually inhibiting Catalase expression [20]. The link between $\alpha$-Klotho and FOXO1 activation via the insulin/IGF-1/ PI3K/Akt pathway has been already proposed by Yamamoto et al. [11]. We further postulate that $\alpha$-Klotho may regulate Catalase expression in a similar manner, via FOXO1. This is supported by the lower Klotho, FOXO1 and Catalase gene expression as well as the lower Catalase activity observed in PBMCs of hypertensives of the present study. Additionally, the direct correlation observed between $\alpha$-Klotho and Catalase expression in hypertensive patients as well as controls also supports this theory. However, studying the exact mechanism at the cellular levels is required to validate this postulation.

As age and obesity are known risk factors in hypertension, we have attempted to attenuate their influence on the study results by recruiting age, gender and BMI matched controls for the hypertensive patients in the study. Another strength of the present study is that by recruiting only newly diagnosed essential hypertensive patients not on anti-hypertensive or any other medication, we attempted to avoid the effects of medication on analysis of the data. However, the majority of the patient population comprised of males. The analyses for males and females done separately (data not shown) were congruous with that of the total patient population analysed in the study.

In conclusion, the present study demonstrated increased oxidative stress, diminished antioxidative capacity in terms of Catalase, decreased soluble $\alpha$-Klotho levels, and decreased $\alpha$-Klotho expression in PBMCs to be associated with essential hypertension. Additionally, a direct correlation between $\alpha$-Klotho and Catalase expression as well as lower expression of FOXO1 transcription factor were also observed in hypertensives. In the light of this relationship between $\alpha$-Klotho and Catalase observed in the present study and the regulatory role of $\alpha$-Klotho in Insulin/ IGF-1 signalling, documented in literature, a-Klotho appears to have an influence on gene expression of Catalase. Thus, the application of $\alpha$-Klotho against oxidative stress related diseases, such as hypertension, assumes great significance and warrants further exploration.

\section{Acknowledgements}

Authors would like to acknowledge, Sir HN Hospital and Research Centre, Mumbai for permitting the recruitment of the patients for the study. The work was supported financially by Sir HN Medical Research Society, Mumbai, India.

\section{Conflicts of interest}

The authors have no potential conflicts of interest, financial or otherwise.

\footnotetext{
References

1. Brown MJ (1996) The causes of essential hypertension. Br J Clin Pharmacol 42: 2127. [Crossref]

2. Beevers G, Lip GY, O'Brien E (2001) ABC of hypertension: The pathophysiology of hypertension. BMJ 322: 912-916. [Crossref]

3. Sun Z (2014) Aging, arterial stiffness, and hypertension. Hypertension 65: 252-256.
}

4. Harvey A, Montezano AC, Touyz RM (2015) Vascular biology of ageing-Implications in hypertension. J Mol Cell Cardiol 83: 112-121. [Crossref]

5. Kuro-o M, Matsumura Y, Aizawa H, Kawaguchi H, Suga T, et al. (1997) Mutation of the mouse klotho gene leads to a syndrome resembling ageing. Nature 390: 45-51.

6. Zhou X, Chen K, Lei H, Sun Z (2015) Klotho gene deficiency causes salt-sensitive hypertension via monocyte chemotactic protein-1/CC chemokine receptor 2-mediated inflammation. J Am Soc Nephrol 26: 121-132.

7. Sopjani M, Rinnerthaler M, Kruja J, Dermaku-Sopjani M (2015) Intracellular signaling of the aging suppressor protein Klotho. Curr Mol Med 15: 27-37.

8. Izhar U, Hasdai D, Richardson DM, Cohen P, Lerman A (2000) Insulin and insulin-like growth factor-I cause vasorelaxation in human vessels in vitro. Coron Artery Dis 11: 69-76.

9. Colao A, Di Somma C, Cascella T, Pivonello R, Vitale G, et al. (2008) Relationships between serum IGF1 levels, blood pressure, and glucose tolerance: an observational, exploratory study in 404 subjects. Eur J Endocrinol 159: 389-397.

10. Birben E, Sahiner UM, Sackesen C, Erzurum S, Kalayci O (2012) Oxidative stress and antioxidant defense. World Allergy Organ J 5: 9-19.

11. Yamamoto M, Clark JD, Pastor JV, Gurnani P, Nandi A, et al. (2005) Regulation of oxidative stress by the anti-aging hormone klotho. $J$ Biol Chem 280: 38029-38034. [Crossref]

12. Wolf I, Levanon-Cohen S, Bose S, Ligumsky H, Sredni B, et al. (2008) Klotho: a tumor suppressor and a modulator of the IGF-1 and FGF pathways in human breast cancer. Oncogene 27: 7094-7105.

13. Ogg S, Paradis S, Gottlieb S, Patterson GI, Lee L, et al. (1997) The Fork head transcription factor DAF-16 transduces insulin-like metabolic and longevity signals in C. elegans. Nature 389: 994-999.

14. Ohta J, Rakugi H, Ishikawa K, Yang J, Ikushima M, et al. (2007) Klotho gene delivery suppresses oxidative stress in vivo. Geriatrics \& Gerontology International. 7: 293299.

15. Lin K, Hsin H, Libina N, Kenyon C (2001) Regulation of the Caenorhabditis elegans longevity protein DAF-16 by insulin/IGF-1 and germline signaling. Nat Genet 28: 139145

16. Giannakou ME, Goss M, Jünger MA, Hafen E, Leevers SJ, et al. (2004) Long-lived Drosophila with overexpressed dFOXO in adult fat body. Science 305: 361. [Crossref]

17. Hwangbo DS, Gershman B, Tu MP, Palmer M, Tatar M (2004) Drosophila dFOXO controls lifespan and regulates insulin signalling in brain and fat body. Nature 429: 562-566. [Crossref]

18. Accili D, Arden KC (2004) FoxOs at the crossroads of cellular metabolism, differentiation, and transformation. Cell 117: 421-426.

19. Lim SW, Jin L, Luo K, Jin J, Shin YJ, et al. (2017) Klotho enhances FoxO3-mediated manganese superoxide dismutase expression by negatively regulating PI3K/AKT pathway during tacrolimus-induced oxidative stress. Cell Death Dis 8: e2972.

20. Venkatesan B, Mahimainathan L, Das F, Ghosh-Choudhury N, Ghosh Choudhury G (2007) Downregulation of catalase by reactive oxygen species via PI 3 kinase/Akt signaling in mesangial cells. J Cell Physiol 211: 457-467. [Crossref]

21. Montuschi P, Barnes PJ, Roberts LJ (2004) Isoprostanes: markers and mediators of oxidative stress. FASEB J 18: 1791-1800.

22. Jacob KD, Noren Hooten N, Trzeciak AR, Evans MK (2013) Markers of oxidant stress that are clinically relevant in aging and age-related disease. Mech Ageing Dev 134: 139-157.

23. Chobanian AV, Bakris GL, Black HR, Cushman WC, Green LA, et al. (2003) The seventh report of the joint national committee on prevention, detection, evaluation, and treatment of high blood pressure: the JNC 7 report. JAMA 289: 2560-72.

24. Livak KJ, Schmittgen TD (2001) Analysis of relative gene expression data using realtime quantitative PCR and the 2(-Delta Delta C(T)) Method. Methods 25: 402-408. [Crossref]

25. Annor FB, Goodman M, Okosun IS, Wilmot DW, Il'yasova D, et al. (2015) Oxidative stress, oxidative balance score, and hypertension among a racially diverse population. J Am Soc Hypertens 9: 592-599.

26. Brito R, Castillo G, Gonzalez J, Valls N, Rodrigo R (2015) Oxidative stress in hypertension: mechanisms and therapeutic opportunities. Exp Clin Endocrinol Diabetes 123: 325-335. 
27. Briones AM, Touyz RM (2010) Oxidative stress and hypertension: current concepts. Curr Hypertens Rep 12: 135-142. [Crossref]

28. Gomes P, Simio S, Lemos V, Amaral JS, Soares-da-Silva P (2013) Loss of oxidative stress tolerance in hypertension is linked to reduced catalase activity and increased c-Jun NH2-terminal kinase activation. Free Radic Biol Med 56: 112-122.

29. Simio S, Gomes P, Jose PA, Soares-da-Silva P (2010) Increased responsiveness to JNK1/2 mediates the enhanced $\mathrm{H} 2 \mathrm{O} 2$-induced stimulation of $\mathrm{Cl}-\mathrm{HCO} 3-$ exchanger activity in immortalized renal proximal tubular epithelial cells from the SHR. Biochem Pharmacol 80: 913-919.

30. Zhan CD, Sindhu RK, Pang J, Ehdaie A, Vaziri ND (2004) Superoxide dismutase, catalase and glutathione peroxidase in the spontaneously hypertensive rat kidney: effect of antioxidant-rich diet. J Hypertens 22: 2025-2033.

31. Schriner SE, Linford NJ, Martin GM, Treuting P, Ogburn CE, et al. (2005) Extension of murine life span by overexpression of catalase targeted to mitochondria. Science 308: 1909-1911. [Crossref]

32. Redón J, Oliva MR, Tormos C, Giner V, Chaves J, et al. (2003) Antioxidant activities and oxidative stress byproducts in human hypertension. Hypertension 41: 1096-1101. [Crossref]

33. Sigfrid LA, Cunningham JM, Beeharry N, Lortz S, Tiedge M, Lenzen S, et al. (2003) Cytokines and nitric oxide inhibit the enzyme activity of catalase but not its protein or mRNA expression in insulin-producing cells. $J$ Mol Endocrinol 31: 509-518.

34. Uddin M, Yang H, Shi M, Polley-Mandal M, Guo Z (2003) Elevation of oxidative stress in the aorta of genetically hypertensive mice. Mech Ageing Dev 124: 811-817. [Crossref]

35. Su XM, Yang W (2014) Klotho protein lowered in elderly hypertension. Int J Clin Exp Med 7: 2347-2350. [Crossref]

36. Navarro-Gonzalez JF, Donate-Correa J, Muros de Fuentes M, Perez-Hernandez H, Martinez-Sanz R, et al. (2014) Reduced Klotho is associated with the presence and severity of coronary artery disease. Heart 100: 34-40.
37. Semba RD, Cappola AR, Sun K, Bandinelli S, Dalal M, et al. (2011) Plasma klotho and cardiovascular disease in adults. J Am Geriatr Soc 59: 1596-1601. [Crossref]

38. Kitagawa M, Sugiyama H, Morinaga H, Inoue T, Takiue K, et al. (2013) A decreased level of serum soluble Klotho is an independent biomarker associated with arterial stiffness in patients with chronic kidney disease. PLoS One 8: e56695.

39. Cheng X, Zhou Q, Lin S, Wu R (2010) Fosinopril and valsartan intervention in gene expression of Klotho, MMP-9, TIMP-1, and PAI-1 in the kidney of spontaneously hypertensive rats. Zhong Nan Da Xue Xue Bao Yi Xue Ban 35: 1048-1056.

40. Xia W, Zhang A, Jia Z, Gu J, Chen H (2016) Klotho contributes to pravastatin effect on suppressing IL-6 production in endothelial cells. Mediators Inflamm 2016: 2193210.

41. Martín-Nunez E, Donate-Correa J, López-Castillo Á, Delgado-Molinos A, Ferri C, et al. (2017) Soluble levels and endogenous vascular gene expression of KLOTHO are related to inflammation in human atherosclerotic disease. Clin Sci 131: 2601-2609.

42. Kuang X, Chen YS, Wang LF, Li YJ, Liu K, et al. (2014) Klotho upregulation contributes to the neuroprotection of ligustilide in an Alzheimer's disease mouse model. Neurobiol Aging 35: 169-178.

43. Essaghir A, Dif N, Marbehant CY, Coffer PJ, Demoulin JB (2009) The transcription of FOXO genes is stimulated by FOXO3 and repressed by growth factors. $J$ Biol Chem 284: 10334-10342. [Crossref]

44. Franz F, Weidinger C, Krause K, Gimm O, Dralle H, et al. (2016) The transcriptiona regulation of FOXO genes in thyrocytes. Horm Metab Res 48: 601-606. [Crossref]

45. Xie Q, Peng S, Tao L, Ruan H, Yang Y (2014) E2F transcription factor 1 regulates cellular and organismal senescence by inhibiting Forkhead box $\mathrm{O}$ transcription factors. Jiol Chem 289: 34205-34213.

46. Kajihara T, Jones M, Fusi L, Takano M, Feroze-Zaidi F, et al. (2006) Differentia expression of FOXO1 and FOXO3a confers resistance to oxidative cell death upon endometrial decidualization. Mol Endocrinol 20: 2444-2455.

47. Awad H, Nolette N, Hinton M, Dakshinamurti S (2014) AMPK and FoxO1 regulate catalase expression in hypoxic pulmonary arterial smooth muscle. Pediatr Pulmonol 49: 885-897.

Copyright: (C2020 Pathare G. This is an open-access article distributed under the terms of the Creative Commons Attribution License, which permits unrestricted use, distribution, and reproduction in any medium, provided the original author and source are credited. 